\title{
Selective Catalytic Oxidation of Aldehydes by a Molybdenum System
}

\author{
Ikram El Amrani * and Ahmed Atlamsani \\ University Abdelmalek Essaadi, Faculty of Sciences - Tetouan, Laboratory of Materials and Interfacial Systems, \\ P.B.: 2121, 93030, Tetouan, Morocco
}

\begin{abstract}
The oxidation of aldehydes with molecular oxygen was investigated in the presence of $\mathrm{MoO}_{2}$ (acac) $)_{2}$ (Bis(acetylacetonato)dioxomolybdenum(VI)), and under mild condition (temperature and pressure). In the oxidation reaction system, the effect of the catalyst has been evaluated. In addition, the factor of solvents was deeply discussed. The process is particularly selective for linear and aromatic aldehydes. Finally, the use of environmentally-friendly oxidation system, including mild conditions and inexpensive oxidant, can make this process very attractive in the fine chemical synthesis.
\end{abstract}

Keywords: $\mathrm{MoO}_{2}(\mathrm{acac})_{2}$; Aldehydes; Carboxylic acids; Oxidation; Molecular oxygen.

\section{Introduction}

The oxidation of aldehydes to carboxylic acids is a fundamental transformation in organic synthesis that can be now accomplished by several oxidizing reagents. However, in most cases, these reagents are very toxic and must be used in stoichiometric amounts 1,2 . The importance of using molecular oxygen, as an oxidant, is driven by both its abundance as well as its affordability and by its potential as an environmentally friendly oxidant that left no byproduct waste. During the last few years, we have been interested in using high oxidation state of transition metals as catalysts for the oxidation with molecular oxygen 3,4 . The chemistry of molybdenum, whose compounds possess oxidation states of molybdenum ranging from (-II) to (VI) and coordination numbers from 4 to 8 leading to a diverse stereochemistry, is very versatile 5,6 . Molybdenum is less toxic and already found its applications as an alternative substitute to some heavy metals including mercury, thallium, and lead ${ }^{7}$.
Furthermore, molybdenum-based catalysts have several important applications in the petroleum and plastic industries ${ }^{8,9}$. In addition, the use of molybdenum catalysts for oxidation is known in the chemical industry worldwide ${ }^{10}$. Research in this direction, apart from helping the understanding of the role of molybdenum and its derivatives in oxo-transfer reactions, has produced numerous methods, which are useful in -organic synthesis ${ }^{11,12}$. Recently, $\mathrm{MoO}_{2}(\mathrm{acac})_{2}$ has been used as an efficient catalyst for several organic transformations. In this paper, we describe the application of $\mathrm{MoO}_{2}(\mathrm{acac})_{2}$ as catalysts of aldehydes oxidation to carboxylic acids.

\section{Results and Discussion}

\subsection{Effect of catalyst}

In this section, the oxidation of octanal was first considered, and the results obtained with selected precursors and/or reaction times are summarized in Table 1. Two tested molybdenum-based precursors (Table 1, Entries 1 and 2) display catalytic activity under mild conditions leading to high yields of octanoic acid.

Table 1. Oxidation of octanal promoted by various precursors. ${ }^{\mathrm{a}}$

\begin{tabular}{|c|c|c|c|}
\hline Entry & Precursors $(\mathbf{m m o l})$ & Conversion $^{\mathbf{b}}(\boldsymbol{\%})$ & Acid Yield $^{\mathbf{b}}(\boldsymbol{\%})$ \\
\hline $\mathbf{1}$ & $\mathrm{H}_{3}\left[\mathrm{PMo}_{12} \mathrm{O}_{40}\right] \cdot \mathrm{aq}$ & 82 & 80 \\
\hline $\mathbf{2}$ & $\mathrm{MoO}_{2}(\mathrm{acac})_{2}$ & 98 & 98 \\
\hline $\mathbf{3}$ & - & - & - \\
\hline
\end{tabular}

${ }^{\mathrm{a}}$ Conditions: octanal $(5 \mathrm{mmol}), \mathrm{AcOH} / \mathrm{H}_{2} \mathrm{O}(4.5 \mathrm{~mL} / 0.5 \mathrm{~mL})$, precursors $(0.062 \mathrm{mmol}), \mathrm{T}=70{ }^{\circ} \mathrm{C}, \mathrm{t}=24 \mathrm{~h}$, $\mathrm{p}\left(\mathrm{O}_{2}\right)=0.1 \mathrm{MPa} .{ }^{\mathrm{b}}$ Conversions and yields were determined by $\mathrm{GC}$ analysis. 
Nevertheless, the recycling of the Mo(VI) species, for both of them, was difficult due to the formation of reduced heteropolyanions ${ }^{13-20}$ or "insoluble molybdenum (V) blues". Furthermore, we observed that the use of $\mathrm{MoO}_{2}(\mathrm{acac})_{2}$ instead of $\mathrm{H}_{3}\left[\mathrm{PMo}_{12} \mathrm{O}_{40}\right]$ aq. Increases the reactivity and therefore the yield of acids which reached $98 \%$ (Entry 2). Blank experiments performed in the absence of precursor show that the octanoic acid cannot be synthesised (Entry 3).

\subsection{Effect of Solvent}

Various solvents have been tested with different properties (non-polar protique and polar aprotic) in the oxidation of octanal with pure dioxygen in the presence of $\mathrm{MoO}_{2}(\mathrm{acac})_{2}$, the results obtained are summarized in Table 2.

Table 2. Effect of solvent on the catalytic oxidation of octanal a.

\begin{tabular}{|c|c|c|c|c|}
\hline Entry & Solvent (mL) & T $\left({ }^{\circ} \mathbf{C}\right)$ & Conversion $^{\mathbf{b}}(\boldsymbol{\%})$ & Acid Yield $^{\mathbf{b}}(\boldsymbol{\%})$ \\
\hline $\mathbf{1}$ & - & 70 & 90 & 86 \\
\hline $\mathbf{2}$ & $\mathrm{H}_{2} \mathrm{O}(5)$ & 70 & 46 & 44 \\
\hline $\mathbf{3}^{\mathbf{c}}$ & $\mathrm{THF}(5)$ & 40 & 98 & 97 \\
\hline $\mathbf{4}$ & $\mathrm{CH}_{3} \mathrm{CN}(5)$ & 70 & 98 & 96 \\
\hline $\mathbf{5}^{\mathbf{d}}$ & $\mathrm{MeOH}(5)$ & 60 & 13 & 80 \\
\hline $\mathbf{6}$ & $\mathrm{AcOH}(5)$ & 70 & 86 & 98 \\
\hline $\mathbf{7}$ & $\mathrm{AcOH} / \mathrm{H}_{2} \mathrm{O}(4,5 / 0,5)$ & 70 & 98 & 12 \\
\hline
\end{tabular}

${ }^{\mathrm{a}}$ Conditions: octanal $(5 \mathrm{mmol}), \mathrm{MoO}_{2}(\mathrm{acac})_{2}(0.062 \mathrm{mmol}), \mathrm{t}=24 \mathrm{~h}, \mathrm{p}\left(\mathrm{O}_{2}\right)=0.1 \mathrm{MPa}$..

${ }^{\mathrm{b}}$ Conversions and yields were determined by GC analysis

c8 h.

$\mathrm{d} 48 \mathrm{~h}$, the product is identified as methyl octanoate.

Note that without solvent, a moderate activity $(86 \%$ yield) is observed but higher than with water (44\%) (Table 2, Entries 1 and 2). It is an exciting outcome considering the environment, since pollutants elimination from an unselective preparation method is always desirable to subsequent treatment ${ }^{21}$.

Hence, using THF as a solvent at $40^{\circ} \mathrm{C}$ (Table 2, Entry 3), yielding significant quantitative conversion $(98 \%)$ and excellent selectivity $(97 \%)$ for the acid product. Nevertheless, it is worthy to note that the $\alpha$-positions of ethers can be easily attacked by molecular oxygen (scheme1). Moreover, THF is not friendly for the environmental point of view, and thus must be handled under strict safety conditions 22 .

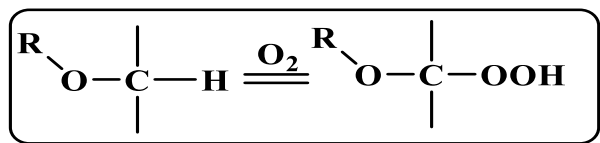

Scheme 1. $\alpha$-positions of ethers can be easily attacked by molecular oxygen
Remarkable conversion of octanal to octanoic acid (98\%) was achieved with acetonitrile (Table 2, Entry 4), whereas in methanol (Table 2, Entry 5) the system only reaches $13 \%$ conversion after $48 \mathrm{~h}$. This could be explained by the ability of $\mathrm{MeOH}$ to form hydrogen bonds that may cause a drawback for the catalytic activity ${ }^{22}$. With pure acetic acid, slightly lower values were obtained (Table 2, Entry 6). When using a mixture of $4.5 \mathrm{~mL}$ of $\mathrm{AcOH}$ and $0.5 \mathrm{~mL}$ of $\mathrm{H}_{2} \mathrm{O}$ (Table 2, Entry 7), the $\mathrm{MoO}_{2}(\mathrm{acac})_{2} / \mathrm{O}_{2}$ system is undoubtedly one of the best for the oxidation of octanal to octanoic acid.

We believe that the solvent effect could be explained by the fact that the solubility of dioxygen differs from one solvent to another. Probably, when the mole fraction of dioxygen increases, the catalytic activity increases ${ }^{21,22}$.

The kinetic curves of $\mathrm{O}_{2}$ consumption in the oxidation of octanal to octanoic acid using $\mathrm{MoO}_{2}(\mathrm{acac})_{2}$ as a catalyst and different $\mathrm{AcOH} / \mathrm{H}_{2} \mathrm{O}$ ratios show that the best activity of our catalyst is obtained with volume ration $\mathrm{AcOH} / \mathrm{H}_{2} \mathrm{O}=4.5 / 0.5$ (Figure 1). 


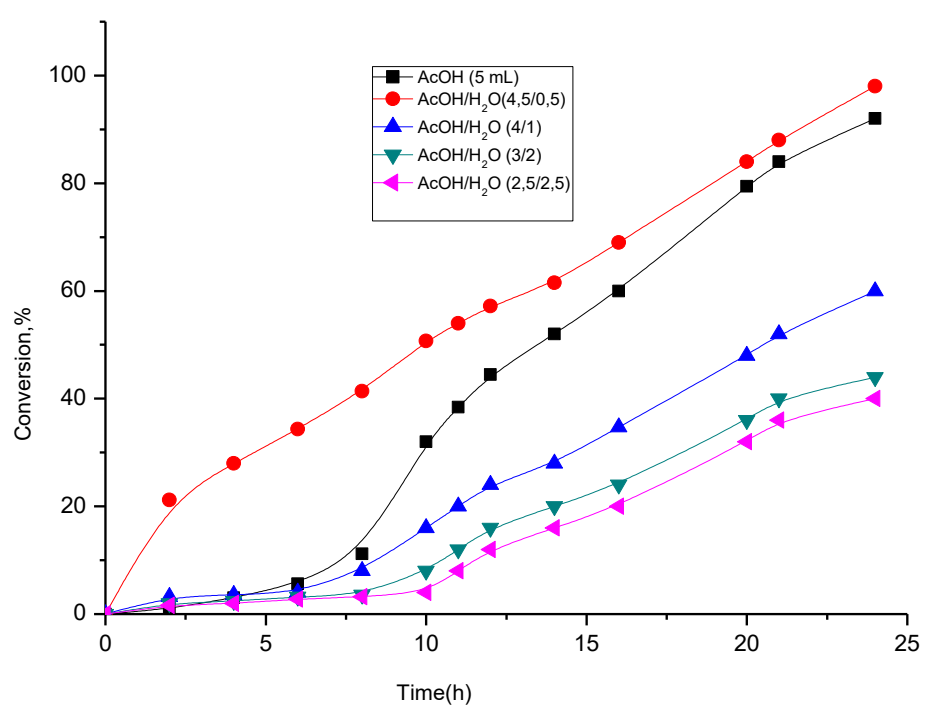

Figure 1. Kinetic curves of $\mathrm{O}_{2}$ consumption with $\mathrm{MoO}_{2}(\mathrm{acac})_{2} / \mathrm{AcOH}-\mathrm{H}_{2} \mathrm{O} / \mathrm{O}_{2}$ system in the oxidation of octanal

\subsection{Catalyst regeneration}

The high selectivity observed in the reaction with octanal and the stability of the product obtained led us to test this aldehyde as a substrate to evaluate the recyclability of the $\mathrm{MoO}_{2}(\mathrm{acac})_{2}$ catalytic system. It is known that the recovery of the catalyst in a homogeneous medium is challenging, and the solubility of $\mathrm{MoO}_{2}(\mathrm{acac})_{2}$ either in organic solvents or in the mixture of acetic acid and water makes difficult the design of a procedure to extract it from the reaction medium. Thus, we carried out successive catalytic runs by sequential addition of substrate loads at the reaction vessel, without isolating the catalyst or the octanoic acid product at the end of each run (Figure. 2).

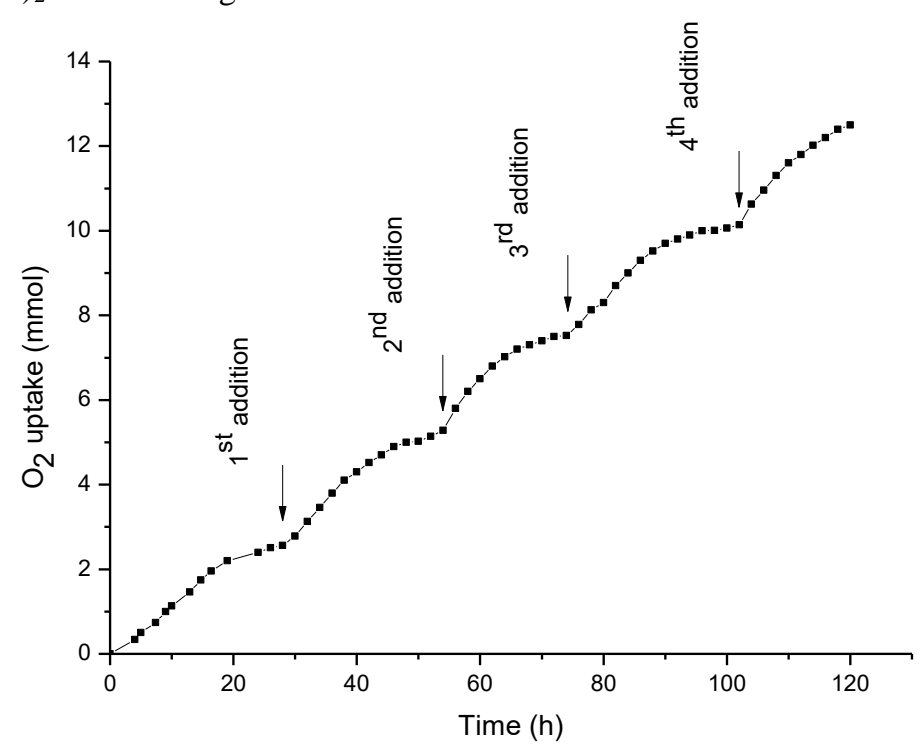

Figure 2. Reuse of the $\mathrm{MoO}_{2}(\mathrm{acac})_{2}$ catalyst in the oxidation of octanal by dioxygen through five successive runs

Conditions: octanal $(5 \mathrm{mmol}), \mathrm{AcOH} / \mathrm{H}_{2} \mathrm{O}(4.5 \mathrm{~mL} / 0.5 \mathrm{~mL}), \mathrm{t}=24 \mathrm{~h}$ per run, $\mathrm{p}\left(\mathrm{O}_{2}\right)=0.1 \mathrm{MPa}$.

Under these conditions, we have shown that the uptake of dioxygen resumes as soon as a new load of the substrate is introduced. Throughout consecutive additions, the consumption profiles of the oxidant $\mathrm{n}\left(\mathrm{O}_{2}\right)=\mathrm{f}$ (time) and the amount of $\mathrm{O}_{2}$ consumed are relatively reproducible. It should be noted that after four successive reuses, the amount of octanoic acid is four times that obtained after the first test, then evidencing that the catalyst is stable through the whole experiment.

\subsection{Oxidation of other aldehydes}

$\mathrm{MoO}_{2}$ (acac) $)_{2}$ was found to be highly active towards the oxidation of both aliphatic and aromatic aldehydes to the corresponding acids using $\mathrm{AcOH} / \mathrm{H}_{2} \mathrm{O}(4.5 / 0.5)(\mathrm{v} / \mathrm{v})$ mixtures in the presence of dioxygen. The results obtained for different substrates are presented in Table 3. 
Table 3. Oxidation of aldehydes to carboxylic acids by $\mathrm{MoO}_{2}(\operatorname{acac})_{2} / \mathrm{O}_{2} / \mathrm{AcOH}-\mathrm{H}_{2} \mathrm{O}$ system ${ }^{\mathrm{a}}$.

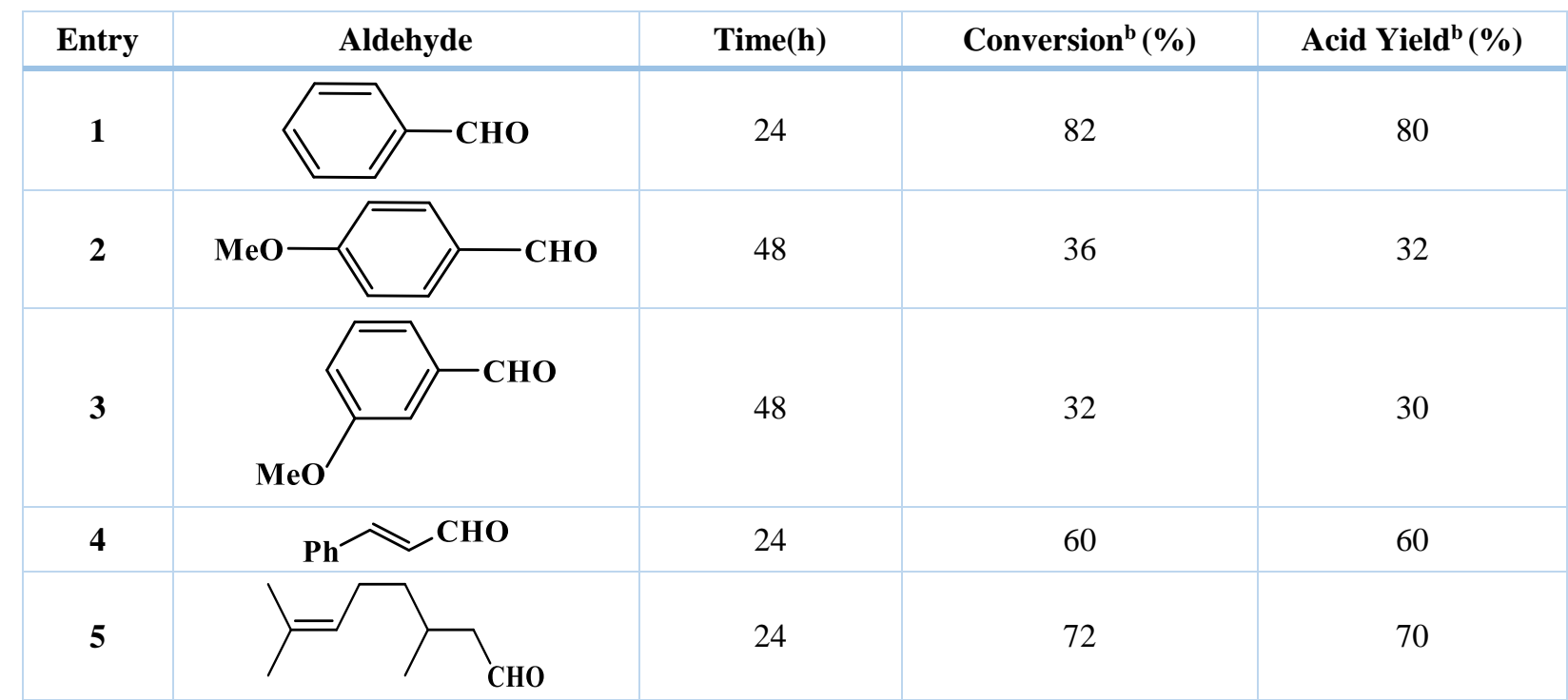

${ }^{\mathrm{a} C}$ Conditions: aldehyde $(5 \mathrm{mmol}), \mathrm{MoO}_{2}(\mathrm{acac})_{2}(0.062 \mathrm{mmol}), \mathrm{AcOH} / \mathrm{H}_{2} \mathrm{O}(4.5 \mathrm{~mL} / 0.5 \mathrm{~mL}), \mathrm{T}=70{ }^{\circ} \mathrm{C}, \mathrm{p}\left(\mathrm{O}_{2}\right)=$ $0.1 \mathrm{MPa}$.

${ }^{\mathrm{b}}$ Conversions and yields were determined by GC analysis.

The treatment of benzaldehyde is selective towards the formation of benzoic acid in high yields (80\%) (Table 3, Entry 1). The use aromatic substrate containing electron-donating substituent (Table 3, Entries 2, 3) cause the reaction rate to decrease dramatically, reaching up to $32 \%$ conversion in $48 \mathrm{~h}$. These observations clearly show that such active electron-donating groups do not allow smooth oxidation of aldehydes to carboxylic acids because these types of aldehyde can also act as radical scavengers 22,23 .

Aiming to explore the chemo-selectivity of $\mathrm{MoO}_{2}(\mathrm{acac})_{2}$, the oxidation of Trans-cinnamaldehyde and citronellal (3,7-dimethyl-6-octenal) was evaluated under the oxidative conditions of our catalytic system (Table 3, Entries 4 and 5) since both of these substrates contain an aldehyde function along with an epoxidisable olefinic double bond. However, the oxidation of citronellal showed a moderate selectivity for the corresponding citronellic acid (Table 3, Entry 5). Further research will also develop toward elucidating the catalytic oxidation mechanism.

\section{Conclusion}

$\mathrm{MoO}_{2}(\mathrm{acac})_{2}$ could catalyze the oxidation of aldehydes with dioxygen. The optimum oxidation condition was carried out using $\mathrm{AcOH} / \mathrm{H}_{2} \mathrm{O}=4.5 / 0.5$ at $70^{\circ} \mathrm{C}$. The main characteristics of our procedure are the appreciable yields of products, the clean reaction profiles (i.e. the excellent selectivity) and the availability of the reagents at low cost and environmentally-friendly conditions which makes it a useful and attractive process for chemical industries. This catalytic system to other oxidation processes is under investigation, with a particular focus on prochiral aldehydes.

\section{Experimental}

The $\mathrm{MoO}_{2}(\mathrm{acac})_{2}$ used in this work was purchased from Aldrich. In a typical experiment, the flasks were filled with $5.0 \mathrm{~mL}$ of the corresponding solvent $\left(\mathrm{CH}_{3} \mathrm{CN}, \mathrm{H}_{2} \mathrm{O}, \mathrm{CH}_{3} \mathrm{OH}, \mathrm{CH}_{3} \mathrm{COOH}\right.$ or a mixture of $\left.\mathrm{CH}_{3} \mathrm{COOH} / \mathrm{H}_{2} \mathrm{O}\right)$ and $\mathrm{MoO}_{2}(\mathrm{acac})_{2}(0,062 \mathrm{mmol})$. The substrate $(5.0 \mathrm{mmol})$ was then added and the flasks were then immersed in an oil bath preheated at $70^{\circ} \mathrm{C}$. Molecular oxygen $\left(\mathrm{O}_{2}\right)$ was added at atmospheric pressure and the mixture was stirred magnetically for the time indicated in the tables. Three parallel catalytic experiments were carried out for each test. The addition of biphenyl as an internal standard at the end of the experiment (except for adipaldehyde and its ester, for which we used methyl heptanoate) permitted to quantitatively analyse the products using a Shimadzu GC-2010 gas chromatograph equipped with a Chiraldex G-TA column (30 m length $\times 25 \mathrm{~mm}$ diameter) and a flame ionization detector. Gas Chromatography conditions include; initial temperature $60^{\circ} \mathrm{C}$ for $5 \mathrm{~min}$; ramp rate $10^{\circ} \mathrm{C} \mathrm{min}{ }^{-1}$; final temperature $170^{\circ} \mathrm{C}$; injection temperature $250^{\circ} \mathrm{C}$ (split mode); detector temperature $250^{\circ} \mathrm{C}$ (detector FID); and carrier gas: a mixture of helium, hydrogen, and air.

\section{References}

1- M. Hudlicky, Oxidations in Organic Chemistry, ACS Monograph Series 186, J. Am. Chem. Soc., Washington, DC, 1990, 174.

2- A. H. Hainess, Methods for the Oxidation of Organic Compounds; Academic: New York, 1988, 221-423.

3- T. Punniyamurthy, S. Velusamy, J. Iqbal, Recent Advances in Transition Metal-Catalyzed Oxidation of Organic Substrates with Molecular Oxygen, Chem. Rev., 2005, 105, 2329-2363. 
4- D. Ramakrishna, B. R. Bhat, Effective Oxidation of Alcohols with $\mathrm{H}_{5} \mathrm{IO}_{6}$ Catalyzed by Nickel(II) Schiff Base Complexes, Synth. React. Inorg. Met. -Org. Nano-Metal Chem., 2010, 40, 516-520.

5- N. N. Greenwood, A. Earnshaw, Chromium, molybdenum and tungsten. In 'Chemistry of the elements' 2nd edn, Elsevier Science., 1997, 1002.

6- E. R. Braithwaite, J. Haber, Molybdenum: An outline of its chemistry and uses. Elsevier, 1994, 9.

7- K. Jeyakumar, D. Kchand, Application of molybdenum (VI) dichloride dioxide $\left(\mathrm{MoO}_{2} \mathrm{Cl}_{2}\right)$ inorganic transformations, J. Chem. Sci., 2009, 121, 111-123.

8- W. W. Williams, J. W. Conley, Organic Pigment, Ind. Eng. Chem., 1955, 47, 1507-1510.

9- W. G. Huckle, E. Lalor, Inorganic Pigments, Ind. Eng. Chem., 1955, 47, 1501-1506.

10-a) J. C. Vedrine, I. Fechete, Heterogeneous partial oxidation catalysis on metal oxides, C. R. Chim., 2016, 19, 1-23.

b) A. V. Biradar, M. K. Dongare, S. B.

Umbarkar, Selective oxidation of primary aromatic alcohols to aldehydes using molybdenum acetylide oxo-peroxo complex as catalyst.Tetrahedron Lett., 2009, 50, 2885-2888

11-(a) D. B. McDonald, J. I. Shulman, Spectrophotometric determination of triphenylphosphine in dilute solutions, Anal. Chem., 1975, 47, 2023-2024.

(b) G. J. J. Chen, J. W. McDonald, W. E. Newton, Synthesis of molybdenum (IV) and molybdenum (V) complexes using oxo abstraction by phosphines. Mechanistic implications, Inorg. Chem., 1976, 15, 2612-2615. (c) C.G. Young, A.G. Wedd, Models of PterinContaining Molybdenum Enzymes, ACS Publications, 1993, 5, 70-82.

(d) A. Nakamura, M. Nakayama, K. Sugihashi, S. Otsuka, Reactivity of oxomolybdenum (VI), - (V), and - (IV) compounds as controlled by sulfur chelate ligands, Inorg. Chem., 1979, 18, 394-400.

12-G. D. Watt, J. W. McDonald, W. E. Newton, Thermochemical studies of molybdenum dithiocarbamate complexes as models for molybdoenzymes, J. Less-Common. Met., 1977, 54, 415-423.
13-Y. Ono, in: J. M. Thomas, K.I. Zamaraev eds., Perspectives in Catalysis (Blackwell Scientific Publications, London), 1992, 431.

14-C. L. Hill, C. M. Prosser-McCartha, Homogeneous catalysis by transition metaloxygen anion clusters, Coord. Chem. Rev., 1995, 143, 407-455.

15-T. Okuhara, N. Mizuno, M. Misono, Catalytic Chemistry of Heteropoly Compounds, Adv. Catal.(Academic Press, New York). 1996, 41, 113-252.

16-R. Neumann, Polyoxometalate Complexes in Organic Oxidation Chemistry, Prog. Inorg. Chem., 1998, 47, 317-370.

17-I. V. Kozhevnikov, Catalysis by Heteropoly Acids and Multicomponent Polyoxometalates in Liquid-Phase Reactions, Chem. Rev., 1998, 98, 171-198.

18-J.-M. Brégeault, F. Launay, A. Atlamsani, Catalytic oxidative carbon-carbon bond cleavage of ketones with dioxygen: assessment of some metal complexes. Some alternatives for preparing $\alpha, \omega$-dicarboxylic acids, C. R. Chim., 2001, 4, 11-26.

19-I. V. Kozhevnikov, "Catalysts for fine chemicals synthesis, Catalysis by Polyoxometalates", John Wiley \& Sons Ltd, The Atrium, Southern Gate, Chichester, England, 2002.

20-J. M. Brégeault, Transition-metal complexes for liquid-phase catalytic oxidation: some aspects of industrial reactions and emerging technologies. Dalton.Trans, 2003, 3289-3302.

21-I. El Younssi, T. Rhadfi, A. Atlamsani, J-P, Quisefit, F. Herbst, K. Draoui, K-10 montmorillonite: An efficient and reusable catalyst for the aerobic CC bond cleavage of $\alpha$-substituted ketones, J. Mol. Catal. A: Chem., 2012, 363, 437-445.

22-I. El Amrani, A. Atlamsani, M. Dakkach, M. Rodríguez, I. Romero, S. Amthiou, Efficient and selective oxidation of aldehydes with dioxygen catalysed by vanadium-containing heteropolyanions, C. R. Chim., 2017, 20, 888-895.

23-I. El Amrani, A. Atlamsani, K-10 montmorillonite: An efficient and reusable catalyst for selective oxidation of aldehydes in the presence of dioxygen, Mediterr.J.Chem., 2019, 8, 380-389. 